\title{
NOTES ON THE TEXT
}

A good many of the people discussed in this book were self-taught or only rather desultorily educated. Often they belonged to the first generation of their immediate family to be literate. As a result their spelling tended to be eccentric and, at times, almost wholly innocent of punctuation. But since one of the themes of the book is writing and its standardization, it did not seem appropriate to censor or "correct" these peoples' efforts. Therefore original spelling, capitalization, and punctuation (or lack of it) have been retained, as have most abbreviations, with the exception of "ye" and "yt" which have been altered to read "the" and "that." Where the text is hard to follow, help is supplied in brackets.

Dates before the introduction of the Gregorian Calendar in $175^{2}$ are given in the Old Style, except that dates falling between January 1 and March 24, inclusive, are rendered with both the old and new year; for example, 28 February $1713 / 14$.

So-called "generic" nouns and pronouns are avoided because they lack specificity. "Man" or "men" and "he" are used when males are being discussed. "Woman" or "women" and "she" are used when females are being discussed. If there is reason to think that a particular observation holds for both women and men, a gender-neutral term such as "people" or "middling sort" is used. This practice has the added advantage of being closer to contemporary usage. Eighteenth-century people were generally quite precise with their gender signifiers, and seldom used terms like "man" to mean anyone other than the males of the species. To argue that they "meant" something more universal substitutes twentieth-century mystifications for early modern candor. 
